\title{
Lo inagotable como premisa, la libertad como horizonte: pensando y aprendiendo con Paulo Freire
}

\section{Inexhaustible as a premise, freedom as the horizon: thinking and learning with Paulo Freire}

\author{
Ramon Marcelino Ribeiro Júnior, * Agustina Rosa Echeverría**
}

Recibido: 13 de julio de 2020 Aceptado: 10 de agosto de 2020 Publicado: 30 de septiembre de 2020

To cite this article: Ribeiro Júnior, R. M. y Rosa Echeverría, A. (2020). Lo inagotable como premisa, la libertad como horizonte: pensando y aprendiendo con Paulo Freire. Márgenes, Revista de Educación de la Universidad de Málaga, 1 (3), 78-90 DOI: $\underline{\text { https://doi.org/10.24310/mgnmar.v1i3.9485 }}$

\section{RESUMEN}

Este trabajo narra momentos importantes del encuentro de sus autores con la obra de Paulo Freire. Tiene la finalidad de presentar una reflexión cuidadosa de temas relevantes del pensamiento educacional freireano y procura responder algunas objeciones que se le presentan. Por esa razón, el texto está estructurado de la siguiente forma: primero, un breve relato del encuentro con la obra de Freire, y sus efectos, de uno de los autores; Segundo: nos concentramos en el concepto de vocación ontológica para “ser más”, base de la antropología filosófica del pensamiento freireano. Tercero: la atención es dedicada a su forma de comprender los contenidos escolares, respondiendo a las acusaciones de no ultrapasar los “conocimientos de la experiencia cotidiana” que le son imputados, destacando los aspectos dialógico, interdisciplinar y contextualizador de su forma de tratar el conocimiento. Cuarto: focalizamos las razones que sostienen con firmeza la fe en el pueblo explícita en la vida y la obra de Freire. Finalmente, coherentes con un pensamiento que es vivo, y fue elaborado en movimiento y para el movimiento, concluimos con preguntas que señalan caminos de futuras reflexiones e investigaciones.

Palabras clave: Paulo Freire; vocación ontológica para "ser más”; contenidos escolares

\section{ABSTRACT}

This work narrates essential moments of the meeting of its authors with the work of Paulo Freire. Its purpose is to present a careful reflection of Freire's educational theory's selected topics and to answer some objections that it offers. Therefore the paper is structured as follows-first, a brief description of one of the authors' experiences with Freire's work. Second, we focus on the concept of ontological vocation to "be more", the basis of the philosophical anthropology of Freire's theory. Third, we focused on the way of understanding school content by responding to accusations of not overriding the "knowledge of everyday experience". It highlights the dialogical, interdisciplinary, and contextualizing aspects of Freire's way of treating knowledge. Fourth: we focus on the reasons that firmly hold the faith Freire had in the people, which is explicit in his life and work. Finally, consistent with a thought that is alive, and was elaborated in movement and for movement, we conclude with questions that point out paths for future reflections and investigations.

Keywords: Paulo Freire; ontological vocation to "be more"; school content 


\section{E S T U D I O Y E N S Y O S}

Los primeros hombres surgidos del mundo animal no tenían esencialmente una libertad diferente a la de los propios animales; pero cada paso dado por el camino de la cultura era un paso hacia la libertad

(K. Marx y F. Engels')

\section{PAULO FREIRE: ¿CON QUÉ VIENE ESE NOMBRE²?}

Ante todo, me gustaría manifestar mi alegría de, por fin, poder decir que he leído a Paulo Freire. ${ }^{3}$ Siempre consideré que el hecho de no conocer la Pedagogía del Oprimido, y otros trabajos del autor, supone una laguna en mi formación. En mi carrera de graduación para formación de profesores con una matriz curricular nueva, recién salida del horno, que rompía con un limitado " $3+1$ ” y distribuía una carga horaria considerable de asignaturas pedagógicas desde el primer semestre de la carrera, aun así no había leído siquiera ${ }^{5}$ un texto de Freire.

Evidentemente, nombre y conceptos de Freire circulaban por el mundo académico y escolar haciéndome saber de su existencia y, vagamente, sobre su significado. Diferentemente de lo relatado por Sergio Guimarães, en el libro Aprendiendo con la Propia Historia, el nombre de Paulo Freire ya no necesita más ser pronunciado "a escondidas” y sus escritos no son considerados subversivos ni circulan clandestinamente. Existen otras razones -entre ellas la propia negligencia del trabajo de Freire- que impiden que muchos estudiantes se relacionen con la obra freireana, pero una vez más (reeditando los años de la dictadura en Brasil), Paulo Freire, patrono de la educación brasileña desde 2012 y uno de los autores más estudiados en el mundo, es blanco de un movimiento de fuerzas de extrema derecha que persiguen su legado ${ }^{6}$.

El primer libro que leí de Freire fue Pedagogía de la Autonomía (Freire, 2015), presente en la lista de textos indicados por el programa de posgrado en que pensaba ingresar. Fue un texto que me dejó huellas; recuerdo que llegué a emocionarme muchas veces con su lectura- como ahora, que vuelvo al autor. Sin embargo, eso no me hizo continuar estudiando la obra freireana. Cinco años después de la primera lectura de la Pedagogía de la Autonomía, especialmente por querer profundizar mis conocimientos y construir una práctica pedagógica más potente en la institu-

1 Texto citado por Lev Vygotsky (1995), en el tomo III de sus obras escogidas.

2 Inspirado en el pasaje del campesino Antônio Cícero de Souza, o Ciço, citado por Carlos Rodrigues Brandão y referido por Freire en la Pedagogía de la Esperanza (Freire, 2014b).

3 Las vidas de los dos autores de este trabajo se cruzan desde 2006, año que comenzaron a trabajar juntos. Sin embargo, esta sección tiene como enfoque la trayectoria del primer autor y por eso fue escrita -diferentemente del resto del texto- usando la primera persona del singular. La segunda autora ya conocía la obra freireana desde mucho antes de los episodios aquí narrados.

4 Ese modelo de formación de profesores era constituido por tres años de asignaturas de conocimientos específicos y solamente un año de asignaturas de conocimientos pedagógicos.

5 Tampoco estudié evaluación. Aún que haya cursado la asignatura “Currículo, cultura y evaluación", no tuvimos tiempo para estudiar evaluación. Por supuesto que los 4 años de licenciatura son solamente una etapa, la más corta, de un tiempo de 30,35 años o más de desarrollo profesional que ocurre en el contexto de lo que llamamos de formación continuada, lo que significa que siempre hay temas y autores importantes que no son discutidos. Por eso, la formación continuada es tan importante, sin embargo, su existencia no es incompatible con la lucha que se realiza por la composición de los currículos de la carrera.

6 El actual presidente de Brasil, Jair Bolsonaro, llegó a afırmar durante su campaña electoral -en 2018- que iba echar a Paulo Freire del Ministerio de la Educación con un lanzallamas. 


\section{E S T U D I O S Y E N S A O S}

ción donde trabajo, principalmente en la modalidad educacional direccionada a los jóvenes y adultos ${ }^{7}$, tuve la oportunidad de cursar la asignatura sobre Paulo Freire en la Facultad de Educación de la Universidade Federal de Goiás. No estoy aquí solamente recreando y reviviendo esos momentos como un "antes" de la asignatura, mas la opción por esa forma de escritura ya es fruto de la lectura y del estilo de Paulo Freire. El escribir como acción creadora, pues, como señala Ernani Maria Fiori en la introducción a la Pedagogía del Oprimido "Paulo Freire es un pensador comprometido con la vida, no piensa ideas, piensa la existencia” (como se citó en Freire, 2014a, p. 11). Yo diría que sus ideas están llenas de existencia. En eso, Freire y las investigaciones narrativas convergen:

Entendemos que esto es un proceso de aprendizaje crítico desde la propia vida que permite proyectar el futuro desde una consciencia diferente de la realidad. En la medida en que la realidad se construye también desde los relatos individuales, la posibilidad de analizar y deconstruir los significados presentes en estos relatos permite una forma distinta de participar en la transformación de la realidad. (Leite y Rivas, 2009, p. 100)

He leído a Paulo Freire como quien se sienta bajo la acogedora sombra de un árbol frondoso (pensaba tanto en el cerrado brasileño, como en los montes de Málaga) y se pone a dialogar amoroso con un anciano andariego que escribe sobre lo que hizo, para quien lo hizo, cómo lo hizo y por qué lo hizo. Una constatación que luego pude hacer fue que no se debe hacer la pregunta "¿y en la práctica, profesor Paulo Freire?”8 porque Paulo Freire es un pensador y escritor de la praxis, un ejemplo de intelectual que busca incesantemente coherencia entre lo que dice y lo que hace.

...defendemos la praxis, la teoría del quehacer, no estamos proponiendo ninguna dicotomía de la cual pudiese resultar que este quehacer se dividiese en una etapa de reflexión y otra distinta, de acción. Acción y reflexión, reflexión y acción se dan simultáneamente. [...] Al ejercer un análisis crítico, reflexivo sobre la realidad, sobre sus contradicciones, lo que puede ocurrir es que se perciba la imposibilidad inmediata de una forma de acción o su inadecuación al momento. (Freire, 2014a, p. 173)

Por lo tanto, me siento continuamente invitado y provocado por él a una reflexión amplia sobre los diferentes aspectos de mi pensar-hacer como profesor y, principalmente, como ser humano. Y delante de las imposibilidad e inadecuación antes referidas, buscar lo que Freire designa “inéditos viables” (Paro, Ventura, y Silva, 2020). El diálogo freireano me hace pensar mi acción pedagógica, y más allá de ella, mi existencia como totalidad.

7 La Educación de Jóvenes y Adultos (Educação de Jovens e Adultos - EJA) en Brasil, es una modalidad de educación escolar ofrecida, en tesis, para todos aquellos que no concluyeron la educación básica obligatoria en la edad considerada adecuada. La modalidad es una conquista histórica de las clases populares, principalmente la modalidad integrada a la formación profesional. El número de plazas ofrecidas todavía es pequeño frente la demanda que se presenta.

8 Quizá aquí, esté sujetándome a objeciones del propio Paulo Freire, pues él afirma en diferentes lugares que es necesario una busca permanente por aproximar lo que decimos de lo que hacemos, en ese sentido el autor reconoce que él también puede eventualmente descuidarse de algún aspecto de esa relación. Las críticas que él acepta con humildad y receptividad son ejemplos de que eso puede acontecer. Lo que sin dudas no puede ser cuestionado es el compromiso del autor con esa coherencia. Freire tampoco economiza críticas a quien promueve un descompaso entre lo que dice y lo que practica: "lo que no se admite es hacer un discurso democrático y antidiscriminatorio y tener una práctica colonial”. (Freire, 2014b, p. 95) 


\section{E S T U D I O Y E N S A Y O}

Pensar en la existencia, repensar la vida, es un posicionamiento que encuentra resonancia entre la denominada tradición de investigación narrativa y biográfica y la perspectiva freireana. De acuerdo con aquella, la educación "no sería otra cosa que crear condiciones que posibiliten experiencias a partir de las cuales narrar una historia que nos permita vivir otros mundos, imaginarnos en ellos, y construir otras realidades” (Suárez y Rivas, 2017, p. 10). Esta concepción que encuentra apoyo en Clandinin y Connelly (2015), paro los cuales "comprender la vida y la experiencia narrativamente es nuestra investigación y nuestro proyecto de vida” (p. 56).

A continuación trataremos algunos de los temas/problemas objeto de reflexión en la obra freireana que están, a veces, reafirmando nuestras concepciones pedagógicas y nuestra lectura de mundo y, otras veces, poniéndonoslas en duda?

\section{2. ¿VOCACIÓN ONTOLÓGICA PARA “SER MÁS”? LO HUMANO EN CUESTIÓN...}

¿Nascemos humanos o necesitamos ser humanizados? ${ }^{10}$ Esa necesidad, tan cara al campo educacional, compartida por diferentes, e incluso, antagónicas perspectivas, ¿no sería la expresión de una contradicción? Al fin y al cabo, ¿cómo volverse aquello que ya se es? Sucede que necesitamos hacer distinciones conceptuales entre dos situaciones interconectadas, pero distintas: la primera se refiere a ser humano como un miembro de una especie; la segunda, a ser humano -en sentido más estricto- como un miembro de un grupo humano específico, del cual heredamos nuestra socialización primaria. Con él, y con su ayuda, constituimos parte del mundo específicamente humano, el mundo de la cultura. Ese segundo proceso, propio de los seres humanos, es aquel sobre el cual Freire se dedica a discutir en detalle, conformando lo que podríamos designar como los fundamentos antropológicos de su concepción de educación.

Freire, no pocas veces, comienza su reflexión sobre algún tópico específico en educación, recordándonos algunos rasgos característicos básicos de nuestra condición humana. Entre ellos nuestra increíble plasticidad, diferentemente de los otros animales, programados y determinados por su base biológica, nosotros somos programados, pero para aprender y, como resultado de esa especificidad, presentamos una plasticidad sorprendente en nuestro comportamiento.

No somos determinados por nuestra herencia biológica, el peso de aquello que podemos ser viene de las relaciones humanas que nos constituyen. Constitución que usamos para interactuar con los otros y con el mundo. Otros que son indispensables, no sólo para nuestra formación, sino para nuestra propia existencia. Pues somos lo que somos por nuestra relación con los otros y con el mundo.

La forma típicamente humana de relacionarse con el mundo, y no solamente estar en contacto con él, es detallada por Freire de modo a explicitar mejor en qué somos diferentes de los otros

9 Cuando me refiero al pensar o al quehacer, como Paulo también lo hace, no sugiero una dicotomía, como él tampoco lo sugiere. Pensar y hacer son praxis. Al fin y al cabo, pensar es una práctica, como se pone evidente en la expresión freireana "práctica de pensar la práctica".

10 Optamos por la expresión "ser humanizado" en contraposición a "humanizarse" que resalta la primacía del ambiente social. No es un proceso que podemos iniciar solos, aunque a partir de cierto momento podemos continuarlo de maneras diversas. Y, al fin de cuentas, ambos se constituyen dialécticalmente. 


\section{E S T U D I O Y E N S A Y O}

animales. Para Freire nosotros somos seres de relación con el mundo: reflexivas, consecuentes, transcendentes y temporales. Otros animales están solamente en contacto con el mundo: reflejos, inconsecuentes, intranscendentes e intemporales (Freire, 1979).

Esos rasgos de la relación que los humanos tienen con el mundo y con los otros están en la base del proyecto educacional freireano de humanización de mujeres y hombres para lanzarlos a alcanzar más, una posibilidad que le está abierta por la historia entendida como reino de la posibilidad.

La deshumanización, que no se verifica sólo en aquellos que fueron despojados de su humanidad sino también, aunque de manera diferente, en los que la despojan, es distorsión de la vocación de SER MÁS. Es distorsión posible en la historia, pero no es vocación histórica. [...] En verdad, si admitiéramos que la deshumanización es vocación histórica de los hombres, nada nos quedaría por hacer sino adoptar una actitud cínica o de total desesperación. La lucha por la liberación, por el trabajo libre, por la desalienación, por la afirmación de los hombres como personas, como "seres para sí” no tendrían significación alguna. Ésta solamente es posible porque la deshumanización, aunque sea un limbo concreto en la historia, no es, sin embargo, un destino dado, sino resultado de un orden injusto que genera la violencia de los opresores y consecuentemente el ser menos. (Freire, 2014b, p. 40)

El concepto de vocación ontológica de “ser más” como vocación humana histórica es una premisa freireana. Su afirmación es, al mismo tiempo la negación del cinismo o de la desesperación que se siguieron a la prevalencia de su contrario. Esa comprensión ubica la perspectiva freireana en un horizonte ampliado de esperanza, una esperanza que acompañó a Paulo Freire en cada uno de los innumerables y variados lugares que el viejo andariego, por voluntad o por necesidad, pasó o tuvo que pasar.

Y la incansable búsqueda por coherencia de Paulo Freire lo lleva a plantear cuestiones que alcanzan la educación en toda su amplitud. La insistencia en buscar la lucidez ante los desafíos y dilemas que componen el proceso educativo es corolario de la comprensión freireana de que tenemos que orientar nuestras acciones teniendo en vista "el fin que se persigue". Relación sobre la cual él pormenoriza afirmando que:

...es necesario que la educación esté -en su contenido, en sus programas y en sus métodos- adaptada al fin que se persigue: permitir al hombre volverse sujeto, construirse como persona, transformar el mundo, establecer con otros hombres relaciones de reciprocidad, hacer la cultura y la historia. [...] Si queremos que el hombre actúe y sea reconocido como sujeto; si queremos que reconozca en sí el poder de transformar la naturaleza y que responda a los desafíos que esta le propone; si queremos que por medio de sus actos sea creador de cultura; si realmente deseamos todo eso, es importante preparar el hombre para ello por medio de una educación auténtica: una educación que libere, que no adapte, domestique ni oprima. Eso nos obliga a rever de forma profunda todos los sistemas tradicionales de educación, los programas y los métodos. El hombre no puede participar activamente de la historia, de la sociedad, de la transformación de la realidad, si no es auxiliado en su toma de consciencia sobre la realidad y sobre su propia capacidad para transformarla. (Freire, 1980, p. 39)

Debido al radicalismo de sus ideas sobre la educación, sea en la escuela o fuera de ella, Paulo Freire no ha escapado de interpretaciones restrictivas y equivocadas de su obra. Destacamos, 


\section{E S T U D I O Y E N S A Y S}

continuando con esta reflexión, una acusación al pensamiento de Paulo Freire que todavía circula con alguna fuerza entre aquellos que no se han dispuesto a leer al autor con seriedad o elaboraron sus posiciones a partir de lo que han escuchado sobre el tema: la idea de que en el pensamiento freireano hay una desconsideración y hasta una desvaloración de los contenidos escolares, en una palabra, que los contenidos no son importantes.

\section{3. ¿EDUCACIÓN SIN CONTENIDO? AQUÍ, A NOSOTROS NOS INTERESA EL CONDIMENTO...}

La idea de "contenidos” es una idea construida desde diferentes abordajes epistemológicos y educativos, sirviendo incluso a perspectivas que no están alineadas con el pensamiento freireano. En este tema estamos de acuerdo con Vygotsky (1995), para quien "si un objeto se utiliza mal eso no significa de ningún modo que no deba utilizarse” (p. 131).

Es conocida la acusación de "basismo" dirigida a la filosofía de la educación freireana. Pero, es difícil encontrar cualquier aspecto en los escritos del autor que sostengan esa posición.

Querría aclarar que, desde mi punto de vista, la ruptura de la tensión, a favor, por ejemplo, de la teoría, involucrando la minimización de la práctica o vice-versa, la ruptura de la tensión a favor de la sabiduría popular o de las bases populares en cuya práctica se genera aquella sabiduría o a favor del saber académico, la ruptura a favor de la autoridad o de la libertad, cualquiera de ellas trabaja definitivamente contra la democracia. [...] El basismo es tan autoritario cuanto el elitismo de algunos líderes denominados progresistas, en el fondo tan reaccionarios cuanto aquellos. (Freire, 1991, p. 134)

Para el autor brasileño nadie, sea clase dominante o dominada, es propietario de la verdad. Los sectarismos de los cuales se nutren, tanto el elitismo como el basismo representan la pérdida de una visión “más dinámica, contradictoria, procesual de la realidad” (Freire, 1991, p. 134). Freire es un autor que se preocupa, debido a su conciencia histórica, por ir más allá de sí mismo, criticando tanto la negación del saber popular cuanto su mitificación, por eso se quedaba perplejo ${ }^{11}$ ante la acusación de "basismo":

Una de esas maneras de criticar la defensa que vengo haciendo de los saberes de la experiencia vivida, que con frecuencia se repite hasta hoy, para mi legítimo asombro, es la que sugiere, o afirma, que en el fondo lo que propongo es que el educador quede girando, junto con los educandos, en torno a sus saberes de sentido común, cuya superación ni se intentaría. Y la crítica de este tenor concluye subrayando el obvio fracaso de esa comprensión ingenua atribuida a mí de la defensa del giro incansable en torno al saber de sentido común. (Freire, 2014b, p. 118)

La pedagogía freireana comparte con otras perspectivas, como la del constructivismo y de la psicología histórico-cultural, una profunda valoración del conocimiento previo de los sujetos de la práctica educativa. Esa presunción incluye educandos y educadores, e incluso los líderes revolucionarios. Para Paulo Freire es imprescindible valorar, conocer y respectar los conocimien-

11 Otro ejemplo de la perplejidad del autor: "Para mí se ha tornado difícil, casi imposible, entender la interpretación de mi respeto a lo local, como negación de lo universal” (Freire, 2014b, p. 116). 


\section{E S T U D I S Y E N S A Y S}

tos de experiencia elaborados por los diferentes sujetos creadores del acto educativo. Conocer, respetar, considerar, criticar buscando aprehender sus determinaciones, sus raíces, premisas e implicaciones en vista de superarlas. Superación que ocurre mientras se desarrolla la aprehensión crítica de los contenidos sistematizados en su sustantividad.

Paulo Freire es un pensador del sujetos-con-otros-sujetos-en-el-mundo, un mundo que es histórico, siendo la historia el reino de la posibilidad, donde hasta la estructura social es marcada no por su inmutabilidad, de la cual resultaría un fatalismo desalentador, sino por la dialéctica entre cambio y permanencia que se alternan continuamente, tanto en el nivel individual como en el nivel colectivo. Esto permite a Freire (2014a) afirmar que "el saber más elaborado del liderazgo se rehace en el conocimiento empírico que el pueblo tiene, al mismo tiempo en que el conocimiento de éste adquiere un mayor sentido en el de aquel” (p. 249).

Ni el saber de los líderes revolucionario, del educador, del educando o cualquier otro está fuera de la temporalidad histórica, eso es un rasgo humano característico. Para que las personas comprendan mejor su situación, los límites del momento histórico en que viven, las artimañas del poder etc. es necesario que amplíen su capacidad de lectura del mundo, de aprehensión de la realidad. Los conocimientos de experiencias vividas deben ser considerados e incorporados en el trabajo educativo como punto de partida, lo que no es incompatible con la introducción de contenidos científicos sistematizados ${ }^{12}$, en el proceso formativo, como puede ser ejemplificado por el concepto, que compone el proceso de elaboración curricular estructurado por temas generadores, de "temas bisagra":

En este esfuerzo de "reducción" de la temática significativa, el equipo reconocerá la necesidad de introducir algunos temas fundamentales, aunque éstos no hayan sido sugeridos por el pueblo, durante la investigación. La introducción de estos temas, cuya necesidad ha sido comprobada, corresponde, inclusive, a la dialogicidad de la educación de que tanto hemos hablado. Si la programación educativa es dialógica, esto significa que también tienen derecho los educadoreseducandos a participar en ella, incluyendo temas no sugeridos. A éstos, por su función, los llamamos “temas bisagra ${ }^{13 ”}$. (Freire, 2014a, p. 161)

El "basismo" atribuido a Freire es de tal forma insostenible que provoca en nuestro autor la necesidad de una respuesta dura, explicitando una vez más su comprensión y su incredulidad ante algunas lecturas que hicieron de su obra.

12 'En el fondo esto tiene que ver con el pasaje del conocimiento en el plano del 'saber de experiencia vivida', del sentido común, al conocimiento resultante de procedimientos más rigurosos de aproximación a los objetos cognoscibles. Y realizar esa superación es un derecho que las clases populares tienen. [...] Lo que no es posible -me repito ahora- es la falta de respeto al sentido común; lo que no es posible es tratar de superarlo sin, partiendo de él, pasar por él". (Freire, 2014b, p. 116)

13 'El 'concepto antropológico de cultura' es uno de estos 'temas bisagra' que liga la concepción general del mundo que el pueblo esté teniendo al resto del programa educativo. Aclara, por medio de su comprensión, el papel de los hombres en el mundo y con el mundo, como seres de transformación y no de adaptación". (Freire, 2014a, p. 161) 


\section{E S T U D I O Y E N S Y O S}

...no hay cómo no repetir ${ }^{14}$ que partir del saber que tengan los educandos no significa quedarse girando en torno a ese saber. Partir significa ponerse a camino, irse, desplazarse de un punto a otro y no quedarse, permanecer. (Freire, 2014b, p. 98)

Lo que Freire cuestiona no son los contenidos, no hay proceso de conocimiento sin objeto de conocimiento, pero determinadas formas de escoger, organizar y trabajar los contenidos. El blanco de la crítica aquí es la concepción, hoy clásica, mundialmente conocida como "educación bancaria”, que es discutida más detalladamente en la segunda parte de la Pedagogía del Oprimido. Algunos cuestionamientos son retomados en la Pedagogía de la Esperanza como podemos verificar a seguir:

Contenidos que sólo son retazos de la realidad, desvinculados de la totalidad en que se engendran y en cuyo contexto adquieren sentido. En estas disertaciones, la palabra se vacía de la dimensión concreta que debería poseer y se transforma en una palabra hueca, en verbalismo alienado y alienante. De ahí que sea más sonido que significado y, como tal, sería mejor no pronunciarla. (Freire, 2014a, p.79)

En el pensamiento epistemológico de Paulo Freire no hay espacio para "palabras huecas"15. Los contenidos en la propuesta freireana, su importancia y lo "pensar correctamente" con ellos y sobre ellos es descrito de forma bella y sintética en el siguiente pasaje de la Pedagogía de la Esperanza:

...y que no se diga que si soy profesor de biología no puedo alargarme en otras consideraciones, que debo enseñar sólo biología, como si el fenómeno vital pudiera comprenderse fuera de la trama históricosocial, cultural y política. Como si la vida, la pura vida, pudiera ser vivida igual en todas sus dimensiones en la favela ${ }^{16}$ o en una zona feliz de los Jardins ${ }^{17}$ de Sao Paulo. Si soy profesor de biología debo, obviamente, enseñar biología, pero al hacerlo no puedo separarla de esa trama. (Freire, 2014b, p. 109)

Esta reflexión nos ayuda a percibir que la propuesta freireana hace justamente lo contrario de aquello que algunos críticos la acusan de hacer. En efecto, él nos convoca a inserir los contenidos específicos (de cualquier área del conocimiento) en el enredo socio-político-cultural que le atribuya sentido y significado. Eso exige la utilización/tratamiento/articulación de más y más temas, conceptos y temas, que provienen de diferentes áreas ${ }^{18}$, una contextualización densa. De hecho, Freire defiende más y no menos contenidos ${ }^{19}$. Paulo Freire (2014b), y también

\footnotetext{
14 Asumimos el mismo riesgo: no hay como no repetir.

15 Existe una preocupación central con el lenguaje en la perspectiva de Freire (2014b), quien afirma: "cambiar el lenguaje es parte del proceso de cambiar el mundo. La relación entre lenguaje-pensamiento-mundo es una relación dialéctica, procesal y contradictoria (p. 94).

16 Conjunto de viviendas de edificación precaria e improvisada, donde viven muchas familias. Son comunes en las periferias de los grandes centros urbanos brasileños.

17 Barrio tradicional y elitista de la ciudad de São Paulo.

18 Implicaciones de esa postura de Freire son el rasgo contextualizador e interdisciplinario de sus propuestas.

19 Pero no es solamente una cuestión aditiva, la cuestión de la "dosificación", de la relación tiempo/contenido y la forma compleja que Freire piensa el currículo (¡Contenidos, sí! Muchos, pero para qué, a favor de quién, contra quién, cómo...) requiere una profundización extra.
} 


\section{E S T U D I O Y E N S A Y O}

los campesinos con quienes aprendió esa metáfora, se interesa "por el condimento, y la sal no es más que una parte del condimento” (p. 99).

Considerando lo que fue discutido hasta aquí, no es sin razón que el educador brasileño de esa forma se refiera a los autores de las críticas a él dirigidas, examinadas y deconstruidas por nosotros en esta sección:

Mi preocupación por el respeto debido al mundo local de los educandos continúa generando, para mi asombro, de vez en cuando, nuevas críticas que me ven sin rumbo, perdido y sin salida en los estrechos horizontes de la localidad. Una vez más, esas críticas son resultado de lecturas mal hechas de mis textos o de lecturas de textos sobre mi trabajo, escritos por quienes me leyeron igualmente mal. (Freire, 2014b, p. 119)

Tras esa discusión percibimos que Freire además de no negar la importancia de los contenidos en la formación humana, también los moviliza y los pone en función de su proyecto de educación como práctica de libertad. Debido a su lucha por justicia social y contra toda forma de opresión, Freire quiere, con el pueblo, no solamente compartir la sal, pero también el condimento. Claramente, por los cuidados en delinear los aspectos de la interacción ${ }^{20}$ con el pueblo a fin de que no se haga una educación no libertadora o no democrática, alertando aún para el autoritarismo que no pocas veces se reviste de educación para la democracia, Freire expresa su profunda fe en el pueblo. La admirable confianza en la capacidad del pueblo es otra premisa fundamental del pensamiento freireano que nos ha impresionado.

\section{4. ¿FE EN EL PUEBLO? ALGO, POR LO MENOS, ESPERAMOS QUE PERMANEZCA: NUESTRA CONFIANZA EN EL PUEBLO}

Una de las más significativas sorpresas que tuvimos leyendo la Pedagogía de la Esperanza fue en relación con una de las críticas direccionadas a la Pedagogía del Oprimido. Ellas se referían a una supuesta ininteligibilidad "casi imposible de entender, y tan rebuscada y elitista que no podía esconder la 'falta de respeto' de Paulo Freire por el pueblo” (Freire, 2014b, p. 103). Cuando leímos ese pasaje, nos quedamos simplemente perplejos. Uno de los rasgos que más nos causó consternación -por su intensidad, respecto, honestidad, dedicación, humildad, belleza y compromiso que expresaba-fue justamente su profunda fe en el pueblo ${ }^{21}$. Fe y esperanza militantes, de quien no cruza los brazos y aguarda, pero de quien va a la lucha, una de las más grandes provocaciones a nuestra consciencia como ella se encuentra configurada actualmente.

En caso de que esa crítica fuera pertinente, Freire no sería un autor de acción-reflexión. Pero todo en su obra apunta lo contrario y el autor no deja de responderla textualmente. La dialogicidad es considerada por Freire no solamente una estrategia metodológica, sino también un principio constitutivo de la esencia de la educación como práctica de libertad. 


\section{E S T U D I O Y E N S A O S}

La defensa del diálogo como esencia de la educación freireana tiene sustentación en diferentes puntos de su pensamiento. Entre esos puntos, destacamos su antropología filosófica, su comprensión de la naturaleza humana como vocación ontológica por "ser más", de la humildad, de la tolerancia, de la solidaridad, de la comunión y de la igualdad fundamental entre las personas como valores constitutivos de lo humano.

Su fe en el pueblo se manifiesta de diferentes maneras, como en su crítica a la arrogancia y al autoritarismo de todos aquellos que actúan contra o en nombre del pueblo, y no con él:

Criticar la arrogancia, el autoritarismo de intelectuales de izquierda o de derecha, en el fondo igualmente reaccionarios, que se consideran propietarios, los primeros del saber revolucionario, y los segundos del saber conservador; criticar el comportamiento de universitarios que pretenden concientizar a trabajadores rurales y urbanos sin concientizarse también con ellos; criticar un indisimulable aire de mesianismo, en el fondo ingenuo, de intelectuales que en nombre de la liberación de las clases trabajadoras imponen o buscan imponer la "superioridad" de su saber académico a las "masas incultas”, esto lo he hecho siempre. (Freire, 2014b, p. 110)

La confianza que Freire tiene en el pueblo, de ningún modo ingenua, no es fruto solamente de su comprensión de lo humano. Está anclada también en experiencias concretas que cruzan el camino formativo del autor. Paulo Freire tenía sensibilidad y escucha atenta para las manifestaciones de los límites, de las ingenuidades, de las fragilidades, pero también de la firmeza y lucidez del pueblo. En este sentido, es emblemática la manifestación de un hombre que tras escuchar a Freire por un tiempo usó la palabra, un derecho que Freire (2014b) defendió desde siempre y, con lucidez y sabiduría, le dio lo que, en sus propias palabras, fue su "o tal vez la lección más clara y contundente que he recibido en mi vida de educador" (p. 35).

Experiencia concreta como fuente de esperanza y del deseo por la liberación del pueblo que vivió también Che Guevara, incorporada por Freire en la Pedagogía del Oprimido y citado con aprobación.

Allí empezaba a hacerse carne en nosotros la conciencia de la necesidad de un cambio definitivo en la vida del pueblo. La idea de la Reforma Agraria se hizo nítida y la comunión con el pueblo dejó de ser teoría para convertirse en parte definitiva de nuestro ser. [...] Nunca han sospechado -concluye con humildad-aquellos sufridos y leales pobladores de la Sierra Maestra, el papel que desempeñaron como forjadores de nuestra ideología revolucionaria. (como se citó en Freire, 2014a, p. 231)

Y comentando el relato de Guevara remata Freire: "Sin embargo, lo que Guevara no expresó, debido quizá a su humildad, es que fueron precisamente esta humildad y su capacidad de amar las que hicieron posible su 'comunión' con el pueblo” (Freire, 2014a, p. 232). La misma humildad y capacidad de amar están en abundancia en Paulo Freire, constituyendo la fuente de su fe en los humanos. Capacidad de amar que lo aleja de una fuente de descreimiento en los humanos, a saber, quitarles el derecho a la palabra ya que "Se desarrolló en el que prohíbe la palabra de los otros una profunda desconfianza en ellos, a los que considera como incapaces” (Freire, 2014a, p.180). 


\section{E S T U D I O Y E N S A Y S}

Regresando a su visión sobre lo humano Freire (1979) obtiene más motivaciones para su fe en las posibilidades abiertas por nuestro inacabamiento ${ }^{22}$.

En base a esta inconclusión nace el problema de la esperanza y la desesperanza. Podemos hacer de éste el objeto de nuestra reflexión. Yo espero en la medida en que me inscribo en la búsqueda, ya que no sería posible buscar sin esperanza. [...] Una educación sin esperanza no es educación. Quien, por ejemplo, no tiene esperanza en la educación de los campesinos, deberá buscar otro trabajo en otra parte. (p. 15)

Además de estas motivaciones está la filiación cristiana de Paulo Freire, nunca negada por él, y vivida de modo que nunca fue obstáculo a su lucha por la transformación social de la mundanidad. La fe freireana en los humanos, en la posibilidad de superación de los límites establecidos por el orden social vigente y en la fuerza de su capacidad creadora, fue un alimento fundamental de sus propuestas y prácticas. Importante destacar un aspecto especial de la "esperanza freireana”, que no es la esperanza de quien observa el transcurso de los eventos, de quien tiene esperanza en la llegada de un mundo mejor sin la necesidad de descruzar los brazos. La esperanza de Freire es una esperanza militante, una esperanza que puede ser educada: "yo venía educando mi esperanza mientras buscaba la razón de ser más profunda de mi dolor. Para eso, jamás esperé que las cosas simplemente se dieran. Trabajé las cosas, los hechos, la voluntad” (Freire, 2014b, p. 42).

Al final de la Pedagogía del Oprimido, con belleza, rasgo característico del texto de Paulo Freire, tenemos una síntesis del sentido de su fe en el pueblo: "Si nada queda de estas páginas, esperamos que por lo menos algo permanezca: nuestra confianza en el pueblo. Nuestra fe en los hombres y en la creación de un mundo en el que sea menos difícil amar” (Freire, 2014a, p. 253). Hoy, podemos afirmar, con alegría, quedaron mucho más que nada, quedaron muchas huellas. Una de ellas es la necesidad que sentimos de educar nuestra esperanza para ampliar nuestra fe en el pueblo y en nosotros mismos.

\section{5. ¡PREGUNTAS! MUCHAS PREGUNTAS PARA COMPARTIR Y SEGUIR INVESTIGANDO}

El enfoque principal de nuestro estudio y esfuerzo investigativo fue comprender Paulo Freire. Por lo tanto, no nos ocupamos con los apuntamientos críticos que eran generados mientras entrábamos en contacto con la obra. Elaboramos, en forma de preguntas, aspectos que deseamos desarrollar en estudios ulteriores.

- Hay en la concepción de comprensión de Freire un compromiso con una epistemología realista. Aun siendo un realismo historicista, ¿qué podría ser obtenido a partir de una lectura pragmática ${ }^{23}$ del pensamiento freireano?

- En un contexto como el de Brasil de hoy, que atraviesa una de las mayores crisis de su historia, en la cual se articulan una perspectiva de Estado crecientemente fascista con

22 Hay un eterno regreso al tema del inagotable, que fundamenta muchos posicionamientos de la propuesta de Freire, desde las primeras obras hasta la PA, su último libro.

23 Aquí nos referimos al pragmatismo filosófico, o neopragamatismo, de Richard Rorty, mi principal objeto de estudio. 


\section{EST U D O S Y E N A Y OS}

una Pandemia de pocos precedentes, en que vivimos la legitimación de ilegalidades, políticas de negación de la ciencia, manifestaciones explícitamente autoritarias contra los poderes legislativo y judicial, y en el cual las fuerzas democráticas no tienen cualquier protagonismo político: ¿cómo mantener la fe en el pueblo?

Tras mucho tiempo estudiando obras y autores del campo del currículo y de la educación en ciencias y matemáticas, fue con Paulo Freire que formulamos la siguiente cuestión:

- ¿No estaríamos gastando toda, o casi toda, nuestra energía discutiendo currículo, discutiendo qué ${ }^{24}$ contenidos tiene que aprender un estudiante que no quiere aprenderlo, pues no le gusta, no ve sentido en estudiar ${ }^{25}$ ? ¿No estaríamos preocupándonos más por conectarnos con los currículos que con los estudiantes? (Rivas, 2009).

Rubem Alves (2004) se refiere a ese problema con la belleza alcanzada por la poesía de Adélia Prado: “No quiero cuchillo, ni queso. ¡Lo que quiero es hambre!” (p. 51). La reflexión sobre esa cuestión me condujo a mi tema/problema para investigaciones futuras y también para la vida: la relación con el saber. Con Paulo Freire aprendemos a decirlo de la siguiente manera: ¿cómo contribuir para que los estudiantes construyan una relación de búsqueda permanente, crítica, creativa, solidaria y amorosa con el saber? Punto de llegada de esa asignatura y punto de partida para los proyectos futuros que planeamos realizar con las, entre otras, alegría y esperanza exigidas por el trabajo de profesor. ¡Necesidad inevitable en un tiempo en que la alegría y la esperanza tienen que ser defendidas con todas nuestras fuerzas!

\section{REFERENCIAS}

Alves, R. (2004). Ao professor, com o meu carinho. Campinas, Brasil: Verus Editora.

Clandinin, D., y Connelly, M. (2015). Pesquisa Narrativa: experiência e história em pesquisa qualitativa. Uberlândia, Brasil: EUFU.

Freire, P. (1991) A Educação na cidade. São Paulo, Brasil: Cortez.

Freire, P. (1979). Educação e Mudança. Rio de Janeiro, Brasil: Paz e Terra.

Freire, P. (1980). Conscientização: teoria e prática da libertação - uma introdução ao pensamento de Paulo Freire. Brasil: Moraes.

Freire, P. (2014a). Pedagogia do Oprimido. Rio de Janeiro, Brasil: Paz e Terra.

Freire, P. (2014b). Pedagogia da Esperança. Rio de Janeiro, Brasil: Paz e Terra.

Freire, P. (2015). Pedagogia da autonomia. Rio de Janeiro, Brasil: Paz e Terra.

\footnotetext{
24 Por una cuestión de simplicidad estamos omitiendo de la formulación las otras cuestiones que atraviesan la discusión curricular, algunas, claramente freireana y que buscan explicar relaciones de poder y dominación que está ahí presentes (a favor y contra qué, a favor y contra quiénes...).
}

25 La pregunta podría ser pensada también teniendo como "objeto" el estudiante futuro profesor. 


\section{EST U D O S Y E N A Y OS}

Leite, A. E., y Rivas, J. I. (2009). Narraciones sobre la universidad: formación y profesión desde la experiencia como estudiante En Rivas, J. I., y Herrera, D. (Ed.), Voz y Educación: la narrativa como enfoque de interpretación de la realidad. España: Octaedro.

Paro, C. A., Ventura, M., y Silva, N. E. K. (2020). Paulo Freire e o inédito viável: esperança, utopia e transformação na saúde. Trabalho, Educação e Saúde, 18(1).

Rivas, J. I. (2009). Narración, conocimiento y realidad: un cambio de argumento em la investigación educativa. En Rivas, J. I., y Herrera, D. (Ed.), Vozy Educación: la narrativa como enfoque de interpretación de la realidad. España: Octaedro.

Suárez, D. H., y Rivas, J. I. (2017). Presentación del Dossier de la Revista del IICE. Revista del IICE, 42, 5-8.

Vygotsky, L. S. (1995). Obras Escogidas: historia del desarrollo de las funciones psíquicas superiores. Tomo III. España: Editorial Visor. 